YOUNG DRIVERS

\title{
Reducing young driver road trauma: guidance and optimism for the future
}

\section{T M Senserrick}

Correspondence to: Dr T M Senserrick, The Center for Injury Research and Prevention at The Children's Hospital of Philadelphia, Philadelphia, PA, USA; senserrick@ email.chop.edu

Accepted 25 April 2006
This paper highlights lessons from each of the Expert Panel papers in the present supplement that provide guidance for future research and initiatives. Although some shortfalls still remain in our understanding, it is argued that much has been learned and we are ready for more translation, implementation, and evaluation of multilevel interventions to help reduce young driver road trauma. Non-use of restraints, speeding, driving at night and with passengers, and fatigue are highlighted as key risk factors to address. "Best practice" intervention is proposed as implementing and strengthening graduated driver licensing systems and complementary candidate programs and research, such as hazard perception training programs. A schematic cognitive-perceptual model to explain the crash sequence process is explored. There is optimism that meaningful impacts can be made, especially coupled with the advances in vehicle technologies, but caution is necessary in the absence of targeted "real world" evaluations and broader implementation and diffusion strategies.
W e are embarking on an exciting new era of young driver research and developments. Promises of advanced vehicle safety technologies are beginning to be realized in the vehicle fleet. Another decade of research has provided a great increase in our understanding of driving, adolescent development, and risk taking, and their overlap in the field of young drivers. Motor vehicle fatalities have fallen to an historic low in the United States; ${ }^{1}$ however, we cannot become complacent. Road trauma remains a leading cause of death of young people both in the US and globally. ${ }^{2}$ So what should we and can we do now to address this issue? The present supplement provides the scientific foundation for identifying key issues and "best practice" recommendations, such that empirically grounded intervention development and evaluation can achieve further meaningful impacts.

The following discussion seeks to integrate key findings in the collective papers of this supplement in order to identify priorities to address young driver road trauma. The context for this discussion includes issues encountered by the author in academic, media, and community circles, including discussions with young drivers and their parents, in her role as a developmental psychologist. The focus is on what can be actioned now based on current learnings.

\section{THE YOUNG DRIVER PROBLEM OR THE PROBLEM YOUNG DRIVER? THE DEBATE CONTINUES}

An early and recurrent debate in young driver research focuses on whether the primary causal crash factor and, therefore, primary target for intervention, is underdeveloped skills due to inexperience- "the young driver problem"-or intentional risk taking associated with adolescence- "the problem young driver". ${ }^{3}$ While both have clearly been established as contributors, ${ }^{4}$ the debate still continues on which is more important. Two recent studies-one from the $\mathrm{US}^{5}$ and one from the $\mathrm{UK}^{6}$ - demonstrate the arguments on both sides.

The studies sought to identify key causes of novice crashes based on police crash reports. The US researchers concluded that the "overwhelming majority" of crashes were due to failure to "employ routine safe operating practices" and failure to recognize the inherent risk rather than "thrill seeking" or deliberate risk taking. In contrast, the UK researchers concluded that a large proportion of crashes resulted from intentional risk taking "rather than any particular failure of skill", and that this was "purely the result of two or three failures resulting from voluntary risk taking", such that they recommended these risks must be addressed for the greatest improvements to be made.

There are several arguments as to why these studies reached different conclusions. Although similar methodologies were employed, there were differences in the age range and experience level of drivers and in the detail available in the crash reports. The necessarily subjective nature of the research could also have contributed to differences. For example, the UK research defined voluntary risks as those that "could be changed at will, if the driver chose to do so or was sufficiently concerned or conscientious about that aspect of the driving task", which fails to take into account that novices may not yet recognize or understand the risk of certain maneuvers, especially those that call on underdeveloped cognitive-perceptual skills. Moreover, four of the top five key causes identified were all failure of skills, suggesting an alternative conclusion was possible. Regardless of potential study differences or limitations, however, the collective papers of this supplement suggest there is a need to move beyond this debate.

There is a clear need to address both inexperience and risk taking, be it intentional or unintentional risk, to have the maximum impact on young driver road trauma. Moreover, underlying these is a multitude of contributing and moderating factors, which, as highlighted by Shope, ${ }^{7}$ are not all amenable to change. The state of the science points to a highly complex, multidimensional problem that needs a multidimensional solution. There is likely no single "silver bullet". As stated by Groeger, ${ }^{8}$ if this were the case the appropriate solution would have long been established. Advances over the past decade do, however, provide clear directives on what can be implemented right now and where further work is needed.

Abbreviation: GDL, graduated driver licensing. 


\section{DEVELOPMENTAL PERSPECTIVES ON RISKY DRIVING}

The UK authors' conclusion focuses on intentional reckless driving by youth, characterized as "showing off", acting like "test pilots" who "push the envelope" of safety boundaries and see what they can "get away with". They seem to chastise youth for perceiving "visible, precise, and stable edges" to this safety envelope. From a developmental perspective, while adolescence is the potential period of change from concrete to logical and abstract thinking, even some adults do not progress to this developmental stage required to grasp hypothetical concepts such as those pertaining to risk taking outcomes and likelihoods. ${ }^{9}$

Exploratory behavior is an essential component of development throughout childhood, such as the way in which toddlers crawling or taking their first steps use their primary care givers as a base from which to explore the world at incrementally further distances away from that safety figure. ${ }^{10}$ Heightened exploratory behavior is an important component of adolescence as one begins to establish further independence from one's parents. Some of this exploration is healthy, such as exploring new career roles and school or extra curricula programs. Some is not, such as smoking, binge drinking, and indeed risky driving. No one would argue this is therefore acceptable, but we must be careful to avoid negative undertones that imply this behavior is simply youth acting irresponsibly.

Further, it is not yet clearly established exactly what proportion of young drivers do drive, or how often they drive, in a deliberately risky manner-is there a subgroup of drivers who always drive in a manner that "pushes the envelope", or is their driving punctuated by spontaneous risk taking episodes? As examined as part of the recent EU ESCAPE initiative, ${ }^{11}$ among all road users a small group of drivers is known to commit many violations and is responsible for many crashes while only accounting for a small fraction of the recorded total of violations and crashes. In contrast, a large number of drivers has no recorded traffic violations yet accounts for a sizeable proportion of crashes. There is no strong support to suggest that this should greatly differ for young drivers. ESCAPE further reached the conclusion that a "considerable amount of traffic violations are committed accidentally and do not involve deliberate risk taking. Many of these violations could be eliminated simply by improving the road infrastructure rather than punishing drivers for something their perceptual-motivational system is not fit for" (page 4). This may well be especially true of young drivers who are new to the system and ill prepared to manage novel traffic conditions and situations.

There is a commonly associated (not unfounded) belief that, while behavior change is challenging and difficult to effect among all populations, this is particularly unlikely to be achievable in relation to youth risk taking. ${ }^{12}$ There have been recent successes, however. In the US, teenage pregnancies are continuing to decrease, ${ }^{13}$ and teenage smoking is at a historically low level. ${ }^{14}$ Other researchers argue that it is possible to direct young people towards other thrilling but lower risk activities, such as extreme sports. ${ }^{15}$ This follows from Berg's discussion in the present supplement of the need to consider higher order goals for life and skills for living. ${ }^{16}$

Adolescence is an exciting developmental period of many changes and new roles. Undertaking the role of driver is one such change. We have a developed a strong basis of understanding of this role. It is time to direct more efforts in applying what we have learned, such that existing and new initiatives can be further developed based on established "best practice" and undergo careful evaluation to determine their true effectiveness and potential impact on road trauma.

\section{WHAT ARE THE PRIMARY FACTORS WE ALREADY KNOW AND CAN ADDRESS?}

Based on international crash statistics and literature as showcased in this supplement, and indeed the US and UK studies, ${ }^{5}{ }^{6}$ several priorities can be identified regarding both inexperience and intentional risk taking factors that should and can be addressed in order to impact young driver road trauma in a meaningful way.

Non-use of restraints and speeding are primary intentional risk behaviors to address in order to reduce crashes and resultant fatalities and injuries. ${ }^{77-19}$ Passenger carriage and night-time driving risk are likely due to both inexperience and risk taking, and exposure, and both should be managed in the early months of independent driving, as advocated by SimonsMorton $^{20}$ and Gillan ${ }^{17}$ and supported by others. ${ }^{78} 19$ Fatigue may also have a profound role, as discussed by Groeger, ${ }^{8}$ and is worthy of effortful attention. Isolating a primary inexperience factor is more difficult; however, hazard perception is clearly inadequately developed in novices, as discussed by Fisher, ${ }^{21}$ and, importantly, as Shope reminds us, ${ }^{7}$ offers a skill that is amenable to change.

Improving visual search and hazard perception skills has promise to achieve a potentially large impact on young driver crashes. Other in press research by Fisher and colleagues ${ }^{22}$ suggests a major difference between novice and experienced drivers is simply time to detect and recognize a hazard when driving, rather than poor selection or enactment of an appropriate response. Young people generally have much faster reflexes than adults. ${ }^{23} 24$ It is possible that risk behaviors such as speeding and close following simply further limit young drivers' ability to detect hazards in due time. The following section explores this proposition further.

\section{A CONCEPTUAL MODEL FOR UNDERSTANDING THE OVER INVOLVEMENT OF YOUNG DRIVERS IN CRASHES}

Figure 1 provides a simple schematic model to conceptualize the potential learning from recent research in the hazard perception field. The base model is predicated on previous research that presents a "crash sequence" of cognitive processing and action that occurs between hazard detection and crash avoidance. ${ }^{23} 24$ This base model is exercised to depict difference in pre-crash and crash sequences for three different driver types, assuming similar traffic conditions and circumstances. The left to right direction represents elapsed time (in seconds) and the $\mathrm{X}$ represents a potential impact. The "driving context and milieu" is included to recognize the multitude of related factors (as particularly discussed by Shope $^{7}$ and Stinson $^{18}$ ) that influence the differing crash sequences (for example, the multilevel circumstances that allow an individual to drive while impaired).

The first diagram depicts a scenario typical of (unimpaired) experienced drivers. Due to attentive visual searching or "scanning" of the traffic environment, the driver detects a potential upcoming hazard-an event or situation, for example-and then a chain of decision making processes occurs. The driver must determine or recognize both that the event or situation is indeed a hazard, and that a reaction is required in order to avoid a collision due to that hazard. Next a response must be selected and enacted such that the crash can be avoided or the severity of the crash minimized. This decision making process and response takes the driver two seconds to complete (in accordance with typical hazard response times established in research ${ }^{24}$ ). The result is that the driver is able to avoid a potential crash, or reduce the severity of an unavoidable crash (therefore, the potential impact, $\mathrm{X}$, is depicted with a broken line).

The second diagram depicts an alternative scenario, which can be conceived of as the same experienced driver in the 

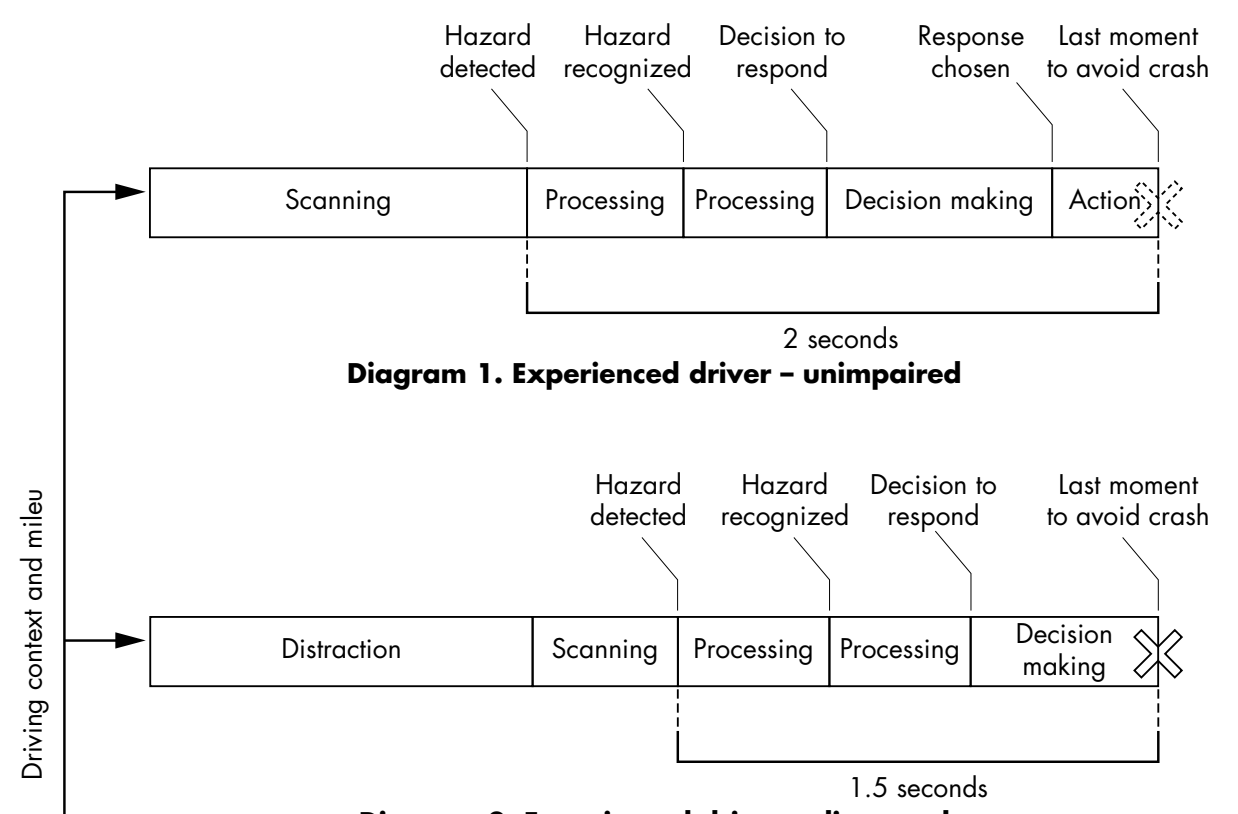

Diagram 2. Experienced driver - distracted

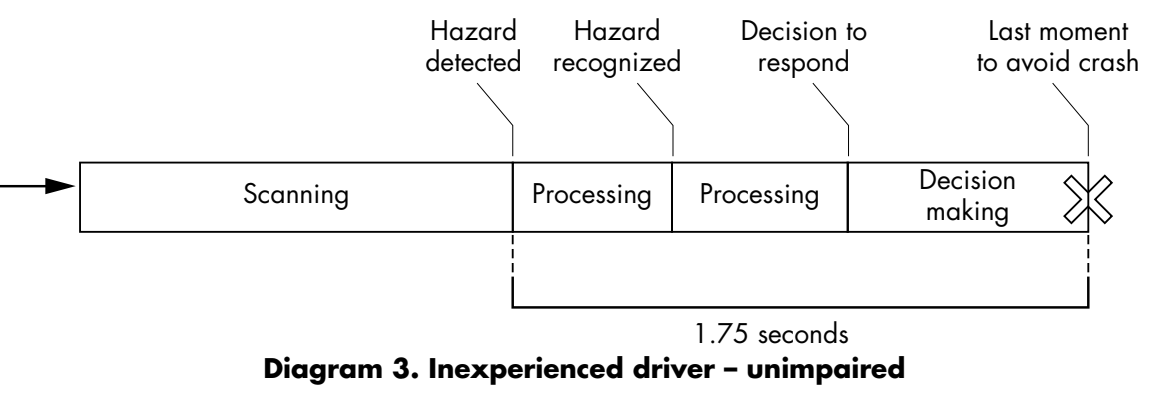

Figure 1 Schematic crash sequence model. Reprinted with the approval of the Center for Injury Research and Prevention.

same traffic environment and circumstances, however, the driver is now distracted. The distraction may be, for example, talking on a cell phone or simply looking at something or someone inside the vehicle and not at the traffic environment. Therefore the driver detects the potential hazard a fraction of a second later than in the first diagram. The driver still requires two seconds to undergo the decision making process through to enacting a response, however, the distraction has delayed detection by half a second and, therefore, only 1.5 seconds are "available". As a result there is a crash that could otherwise have been avoided or have been less severe if the driver had not been distracted and, therefore, perceived the hazard earlier.

The third diagram depicts the potential scenario (in the same traffic environment and circumstances) of a new, inexperienced (unimpaired) young driver. The driver is scanning but not effectively because of their inexperience and, therefore, detects the potential hazard at one quarter of a second delay to the experienced driver in the first diagram. As the driver is inexperienced, each subsequent phase of decision making and response requires a fraction of a second longer than the experienced driver, and therefore the 1.75 seconds "available" are insufficient to avoid or reduce the severity of the crash, and a major crash results.

The contention that all of the pre-crash sequence phases take fractions longer for the inexperienced driver has long been suggested. ${ }^{23}$ Fisher's research ${ }^{22}$ suggests, however, that this might not be the case in all scenarios, such that an alternative depiction of the inexperienced driver could more closely resemble the second diagram of the distracted experienced driver scenario. To take this a step further, the combination of ineffective scanning with distraction or speeding, for example, could be viewed as effecting even longer delays to detection, such as one half of a second, such that a very severe crash could not be avoided despite equally quick processing and response as an experienced driver. The third diagram may more accurately represent the impaired inexperienced driver, for example, due to fatigue, alcohol, or other drug use, and lengthen each phase to the extent that a fatal crash results.

Innovative research such as this offers exciting new targets for program development and evaluation. These preliminary simulator findings and a preliminary on-road validation study $^{21}$ suggest that programs that can improve hazard perception skills and other measures to minimize the time to detection, such as by addressing distractions and time with eyes off road, can have a meaningful impact on reducing the severity of crashes, if not achieving crash avoidance. It may be that advances in vehicles to reduce speeds and vehicle following distances (increasing the driver's field of view) will not only reduce impact speeds, but also reduce crash occurrences due to earlier detection of hazards. Further research is indeed needed, but the targets for intervention and evaluation are highlighted and the technology exists today or in the near future.

Understanding that only fractions of seconds make all the difference between a near crash, minor crash, or severe crash may demonstrate to young drivers why behaviors such as 
dialing a cell phone, reaching for a CD case on the floor, or turning around to face a rear seat passenger while driving are risky activities. It is possible that behaviors such as these are just as common among older, more experienced drivers yet do not similarly impact their crash risk due to better hazard perception skills, including more time with "eyes on road". For example, an early study found that $29 \%$ of novices made glances at an in-vehicle distraction that were lengthier than the maximum glance duration of experienced drivers. ${ }^{25}$ Current and future developments and evaluations offer much promise in elucidating such causal pathways of young driver risk.

\section{WHAT IS CURRENT “'BEST PRACTICE" YOUNG DRIVER INTERVENTION?}

The collective papers of this supplement provide several clear recommendations. Williams ${ }^{19}$ and Gillan ${ }^{17}$ position the success of graduated driver licensing (GDL) as primary. GDL can address both inexperience and deliberate risk taking by including, for example, a minimum learner period and night-time and passenger restrictions, as well as a zero alcohol requirement and stricter penalties or demerit point systems for moving violations. The marked success of GDL in reducing not only crashes, but also fatalities and serious injuries, provides a strong basis on which to build multilevel interventions. Current "best practice" can be viewed as strengthening and expanding GDL and developing supporting interventions that complement its success, while continuing to evaluate, revise, and re-evaluate for both effectiveness and sustainability.

Supporting programs that currently show promise include: parent-teen agreements, as discussed by Simons-Morton, ${ }^{20}$ which can enhance the management of exposure to novices' highest risk driving conditions beyond the impact of GDL; hazard perception training programs, such as that developed by Fisher and colleagues; ${ }^{21} 22$ and social marketing campaigns, as described by Smith, ${ }^{26}$ such as the successful TRUTH antismoking campaign, which can persuasively address underlying motivational orientations specific to young people.

Vehicle technologies that can benefit specific young driver issues include existing and soon to be available technologies. Intelligent seat belt reminder systems have the potential to have a dramatic impact on youth fatalities and serious injuries in the event of a crash, given current trends of lower usage among youth. ${ }^{18}$ Driver and passenger frontal and side curtain air bags can also afford greater occupant protection. Excessive speeds and poor selection of travel speeds and following distances can be targeted with Intelligent Speed Adaptation and Adaptive Cruise Control. The impact of poor driving skills, including perception and attention, can be addressed by anti-lock brakes, electronic stability control, advanced forward collision warning systems, and distraction limiters. Alcohol interlocks are effective in reducing recidivism $^{27} 28$ and should be considered for all DUI offenders. In addition to the above mentioned advances in vehicle technologies, the new range of in-vehicle monitoring systems available on the market may benefit some families, as discussed by Simons-Morton ${ }^{20}$ and others, ${ }^{77}$ although to what extent and for what proportion of families is unknown.

\section{Cautious optimism for the future}

Iterative evaluation and revisions of intervention initiatives offer promise as component parts of multilevel interventions as urged by Williams, ${ }^{19}$ Stinson, ${ }^{18}$ and others. ${ }^{78}{ }^{16}$ Continued improvements in vehicle crashworthiness, as advocated by Gillan, ${ }^{17}$ will offer even greater protection to occupants and other road users (for example, pedestrians ${ }^{29}$ ).

Caution is warranted, however, as young driver specific research and evaluation is essential, particularly to confirm the likely impact of advances in vehicles, given the potential for increased cognitive workload and distraction to the inexperienced driver. Two recent cell phone studies provide examples. A simulator study found novices spent up to $400 \%$ more time with their eyes off the road when they were text messaging than when not text messaging, ${ }^{30}$ and a test track study found $28 \%$ of teenagers failed to stop at an intersection when talking on a cell phone. ${ }^{31}$ This has implications for complex display panels or systems that require greater invehicle attention. Moreover, any benefits will also likely take longer to reach young drivers, as they tend to drive older vehicles. ${ }^{32}$

These and any education and training developments must also be careful not to inflate the sense of control over the driving environment or other such conscious or subconscious processes that can contribute to a risk compensation effect..$^{33}$ Care must also be taken to ensure social marketing campaigns, which target a very specific behavior, do not send mixed messages about the relative importance of that behavior. For example, alcohol-involved driving receives much attention and can be viewed as the leading cause of young driver crashes. In reality, drunk driving is much less common than other risk behaviors such as speeding, in part through the excellent efforts of Mothers Against Drunk Driving and others, as duly noted by Gillan. ${ }^{17}$ Although not yet evaluated, it is possible that an anti-drunk driving campaign might lead to an incorrect assumption by some youth that as long as they are sober they have the skills to manage other risks, such as speeding.

ESCAPE $^{11}$ highlights that much of the compliance with existing traffic rules and regulations is not only a result of voluntary compliance or active policing, but is also due to successful socialization. Drunk driving is now socially unacceptable to the majority-the "Friends Don't Let Friends Drive Drunk" message discussed by Smith ${ }^{26}$ is well accepted. Restraint use is the norm in countries like Australia and Sweden, yet not as strong in the US, and extremely low among US teenagers in some states. ${ }^{34}$ In contrast driving at a few miles or kilometers over the posted speed limit is a highly accepted or tolerated form of speeding and greater efforts will be needed to shift the social norm.

Both optimal and degraded driving conditions must also be recognized, such as the potentially gross sleep deprivation of youth, as highlighted by Groeger. ${ }^{8}$ Initiatives targeting compliance with GDL restrictions and driving agreements will also play an important role, as particularly highlighted by Gillan. ${ }^{17}$ Berg $^{16}$ and Stinson ${ }^{18}$ remind us that such initiatives must go beyond the notion of young drivers as a homogenous group, to address higher order driving skills and life goals and be sensitive to family, neighborhood, community, and societal differences, which may well show differing trends over time. Not the least of these is the variation in ages of licensure among states within the US and among other countries. Different strategies will be necessary for younger versus older novice drivers. Furthermore, in order to scale up any successful program to the young driver population at large, greater efforts are needed which may well require legislative advocacy by such groups as Advocates for Highway Safety $^{14}$ to ensure laws and policies reflect "best practice" recommendations.

\section{CONCLUSIONS}

This paper has sought to identify the most promising targets and intervention approaches at current for reducing young driver road trauma. "Best practice" recommendations should be implemented in a meaningful way that enhances the safety of all young drivers, recognizing the heterogeneity of youth; be it by personality, life goals, and other individual factors reviewed by Shope ${ }^{7}$ and Berg, ${ }^{16}$ or by race, ethnicity, 


\section{About the author}

Teresa M Senserrick joined the Center for Injury Research and Prevention (formerly Traumalink) at the Children's Hospital of Philadelphia as their first staff based Behavioral Scientist in November 2004. Dr Senserrick was trained in developmental psychology and has worked in health and education research for 14 years. Her focus on young driver research developed during her previous $5 \frac{1}{2}$ year appointment at the Monash University Accident Research Centre, Australia. She has researched extensively on young driver education, training, and graduated licensing at a national and international level, including large reviews, evaluations, and policy developments for Australian state and Swedish federal governments. Dr Senserrick received her BA(Hons) degree and $\mathrm{PhD}$ in Behavioural Science from the University of Melbourne, Australia.

neighborhood, and community diversities highlighted by Stinson..$^{18}$ Ongoing rigorous evaluation of current and future intervention strategies is necessary to ensure that maximum benefit with minimal adverse consequence is achieved and that interventions developed for one context (time, place, target subgroup, etc) are appropriate or necessarily adapted for others.

\section{ACKNOWLEDGEMENTS}

This paper was written as part of the Youthful Driver Research Initiative, a collaborative research program between The Center for Injury Research and Prevention at The Children's Hospital of Philadelphia (CHOP) and State Farm Insurance Companies ${ }^{\circledR}$ (State Farm). The views presented in this paper are those of the author(s) and are not necessarily the views of CHOP or State Farm. The author would like to acknowledge Flaura K Winston, $\mathrm{MD}, \mathrm{PhD}$, for her mentorship and guidance and Allan Williams, PhD, and Lauren Hafner, MPH, for their valuable feedback on earlier versions of this paper.

\section{REFERENCES}

1 National Highway Traffic Safety Administration. Traffic safety facts: 2004 data. Available at http://www-nrd.nhtsa.dot.gov/pdf/nrd-30/ncsa/ TSF2004/80991 1.pdf (accessed April 2006).

2 World Health Organization. Injury: A leading cause of the global burden of disease. Geneva, Switzerland: World Health Organization, 1999.

3 Crettenden A, Drummond AE. The young driver problem versus the young problem driver: A review and crash data analysis. Federal Office of Road Safety Contract Report 151, August, 1994.

4 Maycock G, Lockwood CR, Lester J. The accident liability of car drivers, TRL Research Report 315. Crowthorne, UK: Transport Research Laboratory, 1991.

5 McKnight AJ, McKnight AS. Young novice drivers: careless or clueless? Accid Anal Prev 2003;35:921-5.

6 Clarke DD, Ward P, Truman W. Voluntary risk taking and skill deficits in young driver accidents in the UK. Accid Anal Prev 2005;37:523-9.

7 Shope JT. Influences on youthful driving behavior and their potential for guiding interventions to reduce crashes. Inj Prev 2006;12(Suppl 1):i9-i14.

8 Groeger JA. Youthfulness, inexperience and sleep loss: the problems young drivers face and those they pose for us. Inj Prev 2006; 12(Suppl 1):i19-i24.
9 Inhelder B, Piaget J. The growth of logical thinking from childhood to adolescence. New York, NY: Basic Books, 1958.

10 Ainsworth MDS, Blehar MC, Waters E, Wall S. Patterns of attachment: A psychological study of the strange situation. Hillsdale, $\mathrm{NJ}$ : Erlbaum, 1978

11 Mäkinen T, Zaidel DM, Andersson G, et al. Traffic enforcement in Europe: Effects, measures, needs and future. Final report of the ESCAPE consortium. Report to The European Commission. Available at www.vtt.fi/rte/projects/ escape/escape_d10.pdf (accessed March 2006).

12 Wolfe DA, Mash EJ. Behavioral and emotional disorders in adolescents: Nature, assessment, and treatment. New York, NY: Guildford, 2005.

13 Ventura SJ, Abma JC, Mosher WD, et al. Revised pregnancy rates, 1990-97, and new rates for 1998-99: United States. National vital statistics report, Vol 52(7). Hyattsville, Maryland: National Center for Health Statistics, 2003.

14 Johnston LD, O'Malley PM, Bachman JG, et al. Monitoring the Future national results on adolescent drug use: Overview of key findings, 2005. (NIH Publication No.06-5882). Bethesda, MD: National Institute on Drug Abuse, 2006.

15 Zill N, Nord CW, Loomis LS. Adolescent time use, risky behavior and outcomes: An analysis of national data. Report to the United States Department of Health \& Human Services, Westat, September, 1995

16 Berg H-Y. Reducing crashes and injuries among young drivers: what kind of prevention should be focusing on? Inj Prev 2006;12(Suppl 1):i15-i18.

17 Gillan JS. Legislative advocacy is key to addressing teen driving deaths. Inj Prev 2006; 12(Suppl 1):i44-i48.

18 Juarez P, Schlundt DG, Goldzweig I, et al. A conceptual framework for reducing risky teen driving behaviors and associated adverse outcomes. Inj Prev 2006;12(Suppl 1):i49-i55.

19 Williams A. Young driver risk factors: successful and unsuccessful approaches for dealing with them and an agenda for the future. Inj Prev 2006;12(Suppl 1):i4-i8.

20 Simons-Morton B, Ouimet MC. Parent involvement in novice teen driving: a review of the literature. Inj Prev 2006;12(Suppl 1):i30-i37.

21 Fisher D, Pollatsek AP, Pradhan A. Can novice drivers be trained to scan for information that will reduce their likelihood of a crash. Inj Prev 2006; 12(Suppl 1):i25-i29.

22 Pradhan AK, Hammel KR, DeRamus R, et al. The use of eye movements to evaluate the effects of driver age on risk perception in an advanced driving simulator. Hum Factors 2005;47:840-52.

23 Groeger JA. Understanding driving: applying cognitive psychology to a complex everyday task. Hove, UK: Psychology Press, 2000.

24 Olson PL, Sivak M. Perception-response time to unexpected roadway hazards. Hum Factors 1986;28:91-6.

25 Wikman AS, Nieminen T, Summala H. Driving experience and time-sharing during in-car tasks on roads of different widths. Ergonomics 1998;41:358-72.

26 Smith W. Social marketing: an overview of approach and effects. Inj Prev 2006;12(Suppl 1):i38-i43.

27 Beirness DJ. Best practices for alcohol interlock programs. Ottawa, Ontario: Traffic Injury Research Foundation, 2001.

28 Voas RB, Blackman KO, Tippetts AS, et al. Evaluation of a program to motivate impaired driving offenders to install ignition interlocks. Accid Anal Prev 2002;34:449-455.

29 American Honda Motor Co. Safety for Everyone: Leadership in Pedestrian Protection, 2006. Available at http://corporate.honda.com/safety/ details.aspx? id = pedestrian (accessed April 2006).

30 Hosking S, Young K, Regan M. The effects of text messaging on young novice driver performance. Toronto, Canada: First International Conference on Distracted Driving, October 2-5, 2005.

31 Olsen E. Intersection behavior of novice teen drivers and experienced adult drivers, 49th Annual Meeting of The Human Factors and Ergonomics Society, The Royal Pacific, Universal Orlando, Florida, September 26-30, 2005.

32 Ferguson SA. Other high-risk factors for young drivers-how graduated licensing does, doesn't, or could address them. J Safety Res 2003;34:71-77.

33 Gregersen NP. Young drivers' overestimation of their own skill: An experiment on the relation between training strategy and skill. Accid Anal Prev 1996;28:243-50.

34 Womack KN, Trout NH, Davies BJ. Characteristics and conditions of teenage safety belt use, Report No DOT HS 808 676. Washington, DC: National Highway Traffic Safety Administration, 1997. 